\title{
A relação entre valores, práticas organizacionais e confiança de clientes no setor de serviços
}

\author{
Fátima Guardani ${ }^{\mathrm{a} *}$, Maria Luisa Mendes Teixeira ${ }^{\mathrm{b}}$, \\ Diógenes de Souza Bido ${ }^{c}$, José Afonso Mazzon ${ }^{d}$ \\ a*faromito@terra.com.br, Universidade Presbiteriana Mackenzie, Brasil \\ bmalluluisa@gmail.com, Universidade Presbiteriana Mackenzie, Brasil \\ 'diogenesbido@yahoo.com.br, Universidade Presbiteriana Mackenzie, Brasil \\ jjamazzon@usp.br, FEAUSP, Brasil
}

\begin{abstract}
Resumo
Os valores pessoais influenciam o comportamento dos individuos e os valores organizacionais influenciam o desenvolvimento de práticas organizacionais. Contudo, não se observou estudo relacionando esses constructos com a confiança de clientes. Neste trabalho analisou-se, sob a perspectiva de clientes de empresas do setor de serviços, a relação entre os valores organizacionais percebidos, as práticas percebidas e a confiança nas organizações. Após uma pesquisa qualitativa, elaborou-se uma escala de práticas organizacionais percebidas. Procedeu-se à adaptação de uma escala de valores organizacionais e de outra referente à confiança. 0 teste do modelo relativo ao relacionamento entre os construtos foi feito com base em um Survey junto a uma amostra de clientes. Utilizou-se no processamento dos dados o software Lisrel 8.7. Os resultados mostraram que os valores organizacionais percebidos correlacionamse positivamente com as práticas e que ambos os constructos correlacionam-se positiva e significativamente com a confiança dos clientes.
\end{abstract}

Palavras-chave

Valores organizacionais. Práticas. Confiança. Serviços.

\section{Introdução}

A influência dos valores no comportamento dos indivíduos, em suas escolhas e decisões tem sido apontada como relevante por Kluckhohn (1951), Rokeach (1973), Schwartz (1992) e Rohan (2000). No ambiente organizacional, os valores compartilhados pelos membros de uma organização, ao afetarem suas escolhas e decisões, levam ao desenvolvimento de práticas organizacionais (HOFSTEDE et al., 1990; TAMAYO; GONDIN, 1996) e as práticas desempenhadas podem influenciar a confiança dos clientes (RANAWEERA; PRABHU, 2003; HARISALO; HUTTUNEN; MCINERNEY, 2005). Como a prestação de serviços envolve momentos de interação entre clientes e funcionários (HOFFMAN; BATESON, 2003), a questão central colocada neste estudo é: em organizações do setor de serviços - onde essa interação é mais intensa (LOVELOCK; WRIGHT, 2001) - a confiança dos clientes tem relação com os valores e práticas organizacionais por eles percebidos?
Os valores organizacionais referem-se a crenças e prioridades compartilhadas pelos membros de uma organização (TAMAYO; GONDIN, 1996). Todos os indivíduos apresentam um sistema pessoal de valores, formado mediante o convívio na sociedade (ROKEACH, 1973; SCHWARTZ, 1992). No ambiente de trabalho, os membros de uma organização desenvolvem valores compartilhados entre si, os quais, durante a trajetória da organização, levam a práticas específicas de trabalho, por eles julgadas como adequadas e significativas (HOFSTEDE et al., 1990; TAMAYO; GONDIN, 1996). De acordo com Verbeke (2000, p. 589), as práticas organizacionais são “[...] teorias em uso que representam os comportamentos e procedimentos típicos, adotados pelos membros de uma organização". As práticas organizacionais estão ligadas aos valores predominantes na organização, uma vez que expressam tais valores (HOFSTEDE et al., 1990; VERBEKE, 2000). 
Hoffman e Bateson (2003) enfatizam que, durante o processo de prestação de serviços, ocorrem interações entre clientes e funcionários. As experiências decorrentes dessas interações podem interferir na confiança dos clientes (LOVELOCK; WRIGHT, 2001; GRÖNROOS, 2003), a qual se constitui como um dos fatores determinantes para que indiquem uma empresa prestadora de serviços para outros possíveis clientes (WALTER; RITTER, 2003). 0 conceito de confiança é contemplado em várias áreas de estudo e, de acordo com Hernandez e Mazzon (2005) e Hernandez e Santos (2007), trata-se de um constructo multidimensional, formado por seis dimensões da confiança (disposicional; calculativa; institucional; baseada em conhecimento; baseada em características; baseada em identificação).

Este estudo teve por objetivo geral analisar a relação, sob a perspectiva de clientes de empresas do setor de serviços, entre os valores organizacionais percebidos, as práticas organizacionais percebidas e a confiança. Como objetivos específicos, procurou-se identificar: a relação entre valores e práticas organizacionais sob a perspectiva dos clientes; a relação entre os valores organizacionais percebidos e a confiança; e a relação entre as práticas organizacionais percebidas e a confiança. Para tanto, com base em um questionário estruturado, elaborado a partir da revisão de literatura e de uma pesquisa qualitativa, foi realizado um Survey junto a uma amostra de clientes de empresas do setor de serviços. No tratamento dos dados, utilizaram-se análise fatorial e modelagem de equações estruturais. 0 trabalho apresenta-se estruturado nos seguintes tópicos: referencial teórico; procedimentos metodológicos; análise dos resultados; conclusões e referências.

\section{Referencial teórico}

\subsection{Valores e práticas organizacionais}

Os valores pressupõem uma cultura, um grupo e a relação do indivíduo com a cultura dos grupos de convívio, sendo que, por meio da interação social, os indivíduos apreendem os valores que irão se constituir em preferências justificadas moralmente, indicando um sentido do desejável, considerando-se as metas do indivíduo, do grupo e da sociedade (KLUCKHOHN, 1951; ROKEACH, 1973). Schwartz (1994) menciona que os indivíduos desenvolvem valores mediante o processo de socialização, pela interação social dentro dos grupos nos quais convivem e por meio da experiência e aprendizagem individual. Conforme Rohan (2000), os valores funcionam como guias para a sobrevivência no ambiente social.
Os valores organizacionais são definidos como

[...] princípios ou crenças, organizados hierarquicamente, relativos a estados de existência ou a modelos de comportamento desejáveis, que orientam a vida da empresa e estão a serviço de interesses individuais, coletivos ou mistos [...] (TAMAYO; GONDIM, 1996, p. 63).

Meglino e Ravlin (1998) salientam que os valores dos membros de uma organização determinam os valores da organização como um todo e, da mesma forma que os valores pessoais norteiam o comportamento dos indivíduos, os valores de uma organização compõem a sua cultura e indicam o comportamento necessário para sua adaptação e sobrevivência no ambiente. A função dos valores consiste na orientação da organização, guiando o comportamento de seus membros na forma de pensar, agir e sentir, e no julgamento dos demais, constituindo uma espécie de ideologia (TAMAYO; GONDIM, 1996).

Os trabalhos de Kluckhohn (1951) e de Rokeach (1973) referentes aos valores pessoais serviram de base teórica para diversos estudos relacionados aos valores no âmbito organizacional, no entanto, a teoria de Schwartz vem ocupando esse espaço, principalmente no Brasil (TAMAYO; MENDES; PAZ, 2000; OLIVEIRA; TAMAYO, 2004).

Schwartz (1992), tomando por base a teoria de Rokeach (1973), desenvolveu uma teoria de valores humanos básicos, segundo a qual os valores se organizam numa estrutura circular, compreendendo compatibilidades e oposições, formando duas dimensões bipolares. Posteriormente, desenvolveu uma estrutura de valores culturais, resguardando os mesmos princípios de compatibilidade e oposição, porém envolvendo três dimensões (SCHWARTZ, 1999). Tamayo, Mendes e Paz (2000) realizaram estudos sobre valores organizacionais tendo como base a teoria de valores culturais de Schwartz (1999), e Oliveira e Tamayo (2004) fundamentaram suas pesquisas na teoria de valores básicos de Schwartz (1992). Tendo em vista que valores organizacionais são construídos a partir de valores dos indivíduos que compõem a organização, optou-se neste estudo pela abordagem de Oliveira e Tamayo (2004).

Oliveira e Tamayo (2004) desenvolveram o Inventário de Perfis de Valores Organizacionais (IPVO), cuja aplicação, no Brasil, indicou oito fatores referentes aos valores organizacionais: realização (demonstração de competência por parte da organização e de seus empregados); conformidade (respeito às regras $\mathrm{e}$ aos modelos de comportamento estabelecidos); domínio (busca por controle de recursos e posição dominante no mercado); bem-estar dos empregados (preocupação com a qualidade de vida e a satisfação 
dos empregados); tradição (respeito aos costumes e preservação de práticas consagradas); prestígio (busca por admiração e respeito por parte da sociedade); autonomia (estímulo à criatividade e à curiosidade dos funcionários); preocupação com a coletividade (busca por relacionamento honesto com indivíduos próximos à organização e com a comunidade).

De acordo com Tamayo, Mendes e Paz (2000), no sentido de que funcionam como guias para a ação, os valores organizacionais dizem respeito à solução de conflitos entre indivíduos e grupos quanto a metas e interesses, ao próprio funcionamento da organização e à sua relação com o ambiente.

Conforme Hofstede et al. (1990), os valores permeiam a cultura organizacional e estão associados às práticas organizacionais. As práticas organizacionais consistem em manifestações dos valores organizacionais (CALORI; SARNIN, 1991), refletindo-os (LEVIN, 2000). Hofstede et al. (1990) salientam que as práticas organizacionais relacionam-se diretamente aos valores, os quais formam o núcleo da cultura de uma organização. Como apontam Ferreira et al. (2002), as práticas organizacionais estão relacionadas à forma como os membros da organização desempenham suas atividades de trabalho e aos procedimentos que caracterizam as relações com empregados e clientes.

As práticas organizacionais são aprendidas pelos membros de uma organização na realização de tarefas conjuntas, sendo por eles compartilhadas; são flexíveis, possibilitando alterações conforme mudanças no ambiente; e refletem características da organização no que tange à interação com diferentes públicos (VERBEKE, 2000).

\subsection{Confiança}

A confiança de um indivíduo tem relação com suas expectativas positivas quanto ao comportamento dos demais (ROUSSEAU et al., 1998). Goel, Bell e Pierce (2005) consideram que a confiança manifesta-se nas atitudes e nos comportamentos dos indivíduos e requer um relacionamento entre duas ou mais partes, onde as ações de cada parte afetam as demais.

Mayer, Davis e Schoorman (1995) enfatizam que a propensão a confiar varia conforme as características em termos de personalidade e cultura dos indivíduos, além de contextos específicos e das interpretações que fazem das situações. Kramer (1999) considera que a confiança pode ser propiciada por antecedentes (crença do indivíduo na natureza humana e experiências nas interações junto à outra parte), e por condutores (mediação entre as partes por intermediários confiáveis, características percebidas da outra parte, papel que a outra parte desempenha e as práticas que permeiam a interação entre as partes). De acordo com Sirdeshmukh, Singh e Sabol (2002), o desenvolvimento da confiança dos clientes envolve a competência operacional dos funcionários da organização em executar as tarefas; a benevolência operacional ao demonstrar que o interesse dos clientes é mais importante que os interesses da organização; e a orientação em resolver problemas.

Para Harisalo, Huttunen e Mclnerney (2005), a confiança está relacionada a uma expectativa positiva dos clientes quanto ao comportamento da organização, no sentido de acreditarem que obterão os benefícios que esperam e que não serão prejudicados por suas ações. De acordo com Morgan e Hunt (1994), o nível de confiança dos clientes pode ser analisado através do grau de aceitação das regras e políticas da organização, da propensão que apresentam em trocá-la por uma concorrente, da forma como percebem as soluções no caso de situações conflituosas, do julgamento que fazem de que possuem informações adequadas para tomar suas decisões, e da forma como percebem que a organização busca os mesmos objetivos que seus clientes.

0 modelo proposto por Morgan e Hunt (1994) foi tomado como base por Adamson, Chan e Handford (2003) em um estudo no qual identificaram que o nível de confiança dos clientes sofria influências da percepção da importância que a organização lhes atribuía, no sentido de mostrar preocupação em resolver problemas, em resolvê-los prontamente e em demonstrar interesse na manutenção do relacionamento. Ball, Coelho e Machás (2004) argumentam que, para que haja a intenção de um cliente em manter o relacionamento com uma empresa prestadora de serviços, ele precisa acreditar na benevolência e na integridade dessa organização.

Zeithaml, Berry e Parasuraman (1996) salientam que a longevidade do relacionamento entre empresa e cliente favorece a lucratividade, sendo que clientes mais antigos tendem a comprar mais serviços adicionais oferecidos pela empresa e a indicá-la a outros clientes. Garbarino e Johnson (1999), ao fazerem uma distinção entre confiança e comprometimento, estabelecem que a confiança associa-se ao quanto os clientes acreditam na qualidade dos serviços prestados e na integridade de uma organização. Por outro lado, o comprometimento refere-se à identificação, lealdade e preocupação dos clientes para com a organização, sendo gerado pela confiança.

Hernandez e Mazzon (2005) concluíram que a confiança pode resultar de cinco dimensões, por eles identificadas na literatura: confiança disposicional (disposição do indivíduo em confiar, baseada em suas experiências, de um modo geral, com outros indivíduos e situações); confiança calculativa (racionalização do indivíduo quanto aos riscos assumidos e às 
vantagens obtidas junto à outra parte); confiança institucional (crença do indivíduo de que as instituições sociais possam protegê-lo caso a outra parte não cumpra com suas obrigações); confiança baseada em conhecimento (calcada no relacionamento e nas experiências anteriores junto à outra parte); e confiança baseada em características (suportada pela percepção de características que tornam a outra parte confiável). Com o objetivo de investigar a relevância dessas cinco dimensões de confiança, Hernandez e Mazzon (2005) elaboraram uma escala de perfis de confiança.

Em um trabalho posterior, Hernandez e Santos (2007) realizaram um estudo no qual analisaram a confiança disposicional, a confiança calculativa, a confiança baseada em conhecimento e a confiança baseada em identificação, a qual, conforme os autores, refere-se à percepção de similaridades, bem como de valores comuns, o que leva à estima e ao afeto entre as partes. Hernandez e Santos (2007) aprimoraram a escala de perfis de confiança, incluindo itens referentes à confiança baseada na identificação. Conforme esses autores, a análise comparativa dos tipos de confiança com relação à longevidade no relacionamento entre clientes e fornecedores mostrou que a confiança calculativa implica em relacionamentos menos estáveis, no sentido dos clientes apresentarem uma propensão maior a trocarem de fornecedor, sendo que o inverso ocorre no caso da confiança baseada na identificação.

\section{Procedimentos metodológicos}

\subsection{Instrumento de pesquisa e coleta dos dados}

0 presente estudo é de natureza descritiva, no sentido de que teve como objetivo estabelecer relações entre os constructos junto a uma amostra de clientes de empresas do setor de serviços. Para a identificação dos valores organizacionais percebidos pelos clientes foram utilizados itens extraídos do Inventário de Perfis de Valores Organizacionais (IPVO) de Oliveira e Tamayo (2004), os quais apresentaram, no estudo de Oliveira e Tamayo (2004), cargas fatoriais superiores a 0,40 uma vez que, conforme Hair Junior et al. (2005), cargas fatoriais abaixo deste valor apresentam menor importância na relação com seus fatores. Para identificar a confiança dos clientes foi utilizada uma adaptação da escala de perfis de confiança de Hernandez e Mazzon (2005), na versão complementada por Hernandez e Santos (2007).

Para a identificação das práticas organizacionais percebidas pelos clientes, foi elaborada uma escala a partir de categorias extraídas da análise de conteúdo das falas emitidas em quatro grupos de foco, realizados junto a clientes de empresas prestadoras de serviços, onde se buscou identificar comportamentos e procedimentos típicos adotados pelos funcionários na relação com os clientes. Cada grupo foi formado por oito integrantes selecionados conforme seus perfis e experiências como clientes de empresas prestadoras de serviços. A moderação dos grupos foi feita por um facilitador especializado e o tempo de duração de cada grupo foi de 90 minutos, em média.

A realização dos grupos de foco obedeceu às etapas propostas por Bryman (2004), que sugere a seleção dos sujeitos conforme critérios determinados, procedendo-se à gravação e transcrição dos dados para, posteriormente, estabelecer as categorias para análise. $\mathrm{Na}$ elaboração da análise de conteúdo, contemplaram-se os três procedimentos metodológicos sugeridos por Bardin (2004), os quais envolvem: a pré-análise, a exploração do material e o tratamento dos resultados.

Após a análise das categorias, deu-se início à elaboração dos itens do questionário. Para tanto, foram seguidos os passos sugeridos por Aaker, Kumar e Day (2001), os quais consistem em: especificar o que se pretende medir, gerar a maior quantidade possivel de itens, analisar a clareza, relevância e exatidão dos itens, determinar o tipo de escala de avaliação, incluir, excluir e aperfeiçoar os itens, bem como otimizar o tamanho da escala, no sentido de facilitar seu preenchimento pelos respondentes.

A partir das categorias identificadas na análise dos grupos de foco foram gerados 306 itens, os quais foram submetidos a sucessivas avaliações e, após quatro versões, chegou-se a uma escala final composta por 47 itens. No que se refere à classificação dos itens pelos respondentes, optou-se por uma escala do tipo Likert de seis pontos, de acordo com a qual cada respondente deveria identificar o quanto cada item descrevia o que ocorria na empresa por ele escolhida para avaliação.

Com o objetivo de instruir os respondentes quanto ao processo de preenchimento, apresentava-se, inicialmente, uma explicação sobre o estudo. Em seguida, pedia-se ao respondente que escolhesse uma empresa prestadora de serviços da qual fosse cliente. 0 respondente preenchia então o tipo e o nome da empresa escolhida e assinalava a faixa de tempo em que vinha sendo cliente dessa empresa. Em seguida, o respondente deveria completar, primeiramente, os 47 itens da escala referente às práticas organizacionais percebidas na interação com os funcionários da empresa escolhida. Depois, deveria preencher os 41 itens extraídos do Inventário de Perfis de Valores Organizacionais (IPVO) de Oliveira e Tamayo (2004) 
e, em seguida, os 21 itens adaptados da escala de perfis de confiança de Hernandez e Mazzon (2005), complementada por Hernandez e Santos (2007). Por fim, o respondente preenchia seus dados pessoais, incluindo faixa etária, sexo, grau de instrução, estado civil e renda familiar.

Para a determinação do tamanho da amostra, foram seguidas as recomendações de Hair Junior et al. (2005), que indicam a proporção ideal de 10 respondentes por item de cada escala, com o objetivo de se realizar a análise fatorial exploratória. Sendo assim, como a maior escala (de práticas organizacionais percebidas) era composta por 47 itens, buscou-se um número mínimo de 470 respondentes. A amostra caracterizou-se como não probabilística, sendo que o preenchimento dos questionários ocorreu por meio da distribuição dos mesmos junto a indivíduos que funcionaram como multiplicadores. Ao todo, contou-se com o auxílio de 23 multiplicadores, instruídos a entregar os questionários a clientes de empresas prestadoras de serviços que residissem na região metropolitana de São Paulo e que tivessem, pelo menos, grau de instrução superior incompleto e faixa etária entre 18 e 70 anos. Dessa forma, foram obtidos 516 questionários preenchidos adequadamente.

\subsection{Tratamento dos dados}

Os 516 questionários preenchidos tiveram suas respostas digitadas no software SPSS, versão 15.0. Após a digitação, foi realizada uma análise dos dados, buscando-se identificar a existência de observações atípicas (outliers) e de dados faltantes (missings) que pudessem gerar vieses nas análises posteriores. Foram eliminados 13 questionários, restando então na base de dados 503 casos. Em seguida, foram realizados os procedimentos de estatística descritiva, com o objetivo de observar a distribuição dos dados das escalas e de caracterização da amostra, bem como as principais medidas de tendência central.

Procedeu-se então à análise fatorial exploratória dos resultados de cada parte do instrumento de pesquisa (os 41 itens relativos aos valores organizacionais; os 47 itens referentes às práticas organizacionais e os 21 itens relativos à confiança), levando à identificação dos componentes principais, a partir das correlações entre as variáveis que compunham cada parte, com o objetivo de se analisar as interrelações entre as variáveis e explicá-las conforme suas dimensões latentes.

Apesar dos valores organizacionais e da confiança apresentarem estrutura fatorial conhecida de estudos anteriores, a presente pesquisa é distinta do que foi feito até o momento, uma vez que a coleta de dados foi realizada junto a clientes de organizações do setor de serviços. Por isso, assumir que a estrutura fatorial seria a mesma foi considerada uma suposição questionável e decidiu-se identificar os valores organizacionais percebidos e as dimensões da confiança por meio da análise fatorial exploratória.

Para a realização da análise fatorial exploratória foram seguidas as recomendações de Hair Junior et al. (2005). Sendo assim, após a extração de componentes principais, procedeu-se à rotação varimax e à oblimin, comparando-se os resultados em função da distribuição das cargas fatoriais face às dimensões teóricas existentes. Também se observou como critério de análise que a medida de adequação da amostra (KMO) deveria ser superior a 0,70 ; a variância explicada pelos fatores deveria corresponder no mínimo a 50\%; cada fator extraído deveria apresentar eigenvalue superior a 1,0 ; as cargas fatoriais deveriam ser superiores a 0,50 ; as comunalidades superiores a 0,60 e a confiabilidade da escala, medida através do alfa de Cronbach, superior a 0,60.

Cada fator extraído tornou-se uma nova variável (escore fatorial), que passou a incorporar o banco de dados. Com a utilização do software LISREL, versão 8.7, foram traçadas as relações entre os fatores, através da técnica de modelagem de equações estruturais. Essa forma de tratamento, de acordo com Hair Junior et al. (2005, p. 470), distingue-se por duas características:

[...] estimação de múltiplas e interrelacionadas relações de dependência; e habilidade para representar conceitos não observados nessas relações e explicar erros de mensuração no processo de estimação.

Assim, considerando-se os resultados da análise fatorial e o fato de que as escalas continham 109 variáveis, optou-se por trabalhar os escores fatoriais como indicadores reflexivos de cada um dos respectivos constructos (TABACHNICK; FIDELL, 2001; HAIR JUNIOR et al., 2005).

Dessa forma, cada um dos escores fatoriais foi tratado como variável, constituindo-se como indicadores reflexivos de cada um dos conceitos não observáveis, ou variáveis latentes (valores organizacionais percebidos, práticas organizacionais percebidas e confiança, respectivamente), com o objetivo de se identificar um modelo com vistas ao entendimento da relação.

Os escores fatoriais, quando são usados na modelagem de equações estruturais, são denominados de parcelas (item parcels) e têm algumas vantagens em relação ao uso dos itens propriamente ditos, como maior confiabilidade e menor probabilidade de violar as suposições quanto à distribuição dos dados. Little et al. (2002) discutem as vantagens, desvantagens e formas de se construir essas parcelas. 
A elaboração do modelo seguiu uma abordagem exploratória, que é reconhecida por Jöreskog e Sörbom (1993) como geração de modelos. No processo de identificação do modelo, procurou-se seguir as medidas de ajuste sugeridas por Hair Junior et al. (2005): raiz do erro quadrático médio de aproximação (RMSEA) entre 0,05 a 0,08; índice de qualidade de ajuste calibrado (GFI) maior ou igual a 0,90 ; índice de ajuste não normado (NNFI) maior ou igual a 0,90 ; índice de ajuste normado (NFI) maior ou igual a 0,90 ; e os indices de ajuste relativo (RFI), de ajuste incremental (IFI), de ajuste comparativo (CFI) e de qualidade de ajuste (AGFI), entre 0 e 1, dando-se preferência a modelos com valores mais próximos de 1 .

\section{Análise dos resultados}

\subsection{Caracterização da amostra}

Os respondentes dividiram-se de forma equilibrada entre ambos os gêneros, sendo que a amostra foi composta por $51,5 \%$ de indivíduos do sexo masculino e $48,5 \%$ do sexo feminino. Quanto ao estado civil, 50,7\% são casados, 40,8\% solteiros e 8,5\% separados. Em termos de grau de instrução, a amostra resultou em $82,9 \%$ de indivíduos com superior completo e $17,1 \%$ superior incompleto. A maior parte dos respondentes $(64,0 \%)$ encontra-se na faixa etária de 26 a 40 anos. No que se refere à distribuição por faixas de renda familiar, a maioria $(66,7 \%)$ situa-se entre $\mathrm{R} \$ 4.000,01$ e $\mathrm{R} \$ 10.000,00$.

Os tipos de serviços escolhidos para avaliação pelos respondentes contemplaram variados ramos de atividade. No entanto, as organizações prestadoras de serviços financeiros (bancos, administradoras de cartões de crédito e seguradoras), juntamente com serviços de telefonia (telefonia fixa e móvel), corresponderam a $44,0 \%$ das escolhas dos respondentes. Os demais serviços (alimentação, entretenimento, ensino, turismo, saúde, estética, lazer, transportes) representaram $60,0 \%$ da amostra, porém cada um deles correspondeu a menos de 10,0\%. Quanto ao tempo em que têm sido clientes das organizações escolhidas para avaliação, 90,7\% dos respondentes escolheram empresas das quais têm sido clientes há mais de um ano, evidenciando, dessa forma, experiência de relacionamento suficiente para efetuar as avaliações requeridas pelo instrumento de pesquisa.

\subsection{Análise fatorial dos valores organizacionais percebidos}

As variáveis que compõem os valores organizacionais percebidos pelos clientes mostraram-se adequadas $(\mathrm{KMO}=0,971)$ e foram obtidos cinco fatores, cuja variância explicada foi de $68,2 \%$. Os resultados encontram-se na Tabela 1.

0 fator 1 recebeu o nome Respeito aos stakeholders, por ser composto por valores percebidos relativos à preocupação da organização para com a coletividade, incluindo valores de benevolência e universalismo, a busca por relacionamentos justos, honestos e igualitários para com indivíduos e comunidade e a promoção do bem-estar social. Esse fator também inclui valores de conformidade por parte da organização, no que tange ao respeito às regras e aos modelos de comportamento, às boas maneiras e aos costumes.

lgualmente fazem parte desse fator valores percebidos no que tange à realização por meio da valorização do sucesso e da demonstração de competência, incluindo-se a importância dada à demonstração das habilidades e conhecimentos, bem como o incentivo ao sucesso profissional e ao trabalho competente dos funcionários.

Também estão incluídos no fator 1 os valores relativos à autonomia, à autodeterminação e à estimulação, referindo-se à inovação, ao fornecimento de produtos e serviços respeitados pelos clientes e ao estímulo para que adquiram produtos e serviços novos.

0 fator 2, denominado de Domínio e poder, refere-se aos valores relativos à busca, pela organização, do controle de pessoas e recursos, de posição dominante no mercado, visando à riqueza, à obtenção de lucros e à eliminação da concorrência.

0 fator 3, chamado de Bem-estar dos empregados, expressa valores percebidos relacionados à preocupação, por parte da organização, com aspectos que dizem respeito ao bem-estar e ao hedonismo, dentre eles a qualidade de vida dos funcionários, suas atividades de lazer e diversão, bem como o prazer e a satisfação que obtêm no trabalho.

0 fator 4 recebeu a denominação de Tradição e prestígio, por incluir valores percebidos de busca, por parte da organização, por admiração e respeito na sociedade, bem como tradição no mercado.

0 fator 5 recebeu o nome de Aversão a mudanças, por reunir valores relacionados à manutenção da forma de trabalho e à preocupação em se evitar mudanças na organização.

Tabela 1. Resultados fatoriais de valores organizacionais percebidos.

\begin{tabular}{cccc}
\hline Fator & Autovalor & $\begin{array}{c}\text { \% variância } \\
\text { explicada }\end{array}$ & $\begin{array}{c}\text { Alfa de } \\
\text { Cronbach }\end{array}$ \\
\hline 1 & 18,482 & 33,6 & 0,970 \\
2 & 4,668 & 11,1 & 0,857 \\
3 & 2,061 & 9,3 & 0,893 \\
4 & 1,710 & 9,2 & 0,862 \\
5 & 1,035 & 5,0 & 0,701 \\
\hline
\end{tabular}

Fonte: Elaborada pelos autores. 
$\mathrm{Na}$ comparação desses cinco fatores com os resultados obtidos na análise realizada no estudo de Oliveira e Tamayo (2004), a qual havia resultado em oito fatores referentes aos valores organizacionais, chegou-se às relações apresentadas no Quadro 1.

A comparação entre os fatores correspondentes permite identificar que, do ponto de vista dos clientes, os valores organizacionais apresentam uma divisão diferente da resultante das análises feitas junto aos empregados, no estudo de Oliveira e Tamayo (2004).

Os valores percebidos pelos clientes contemplam, em um mesmo fator: preocupação com a coletividade, conformidade, realização e autonomia. A composição desse fator parece mostrar que, do ponto de vista dos clientes, alguns aspectos se reúnem no sentido de caracterizar uma organização conforme valores de justiça, honestidade, competência e iniciativa.

No que se refere aos valores percebidos de bem-estar dos empregados, observa-se que há congruência com os resultados obtidos por Oliveira e Tamayo (2004). Os valores percebidos pelos clientes referentes ao bem-estar dos empregados encontram-se separados dos relativos ao respeito aos stakeholders, mostrando que os clientes identificam esses valores de uma forma específica e que percebem uma distinção entre a preocupação das organizações para com os stakeholders e os princípios que as guiam na relação com seus empregados.

Os valores percebidos de tradição e prestígio e de domínio e poder também mostram correspondência com o estudo anterior, evidenciando que os clientes identificam princípios diferentes no que tange à busca das organizações por admiração e prestígio e, por outro lado, por domínio e poder. Também cabe destacar que o fator aversão às mudanças contempla a identificação dos clientes de princípios relativos a uma postura de acomodação no mercado e na forma de trabalho das organizações.

Quadro 1. Comparação com Resultados de Oliveira e Tamayo (2004).

\begin{tabular}{|l|l|}
\hline $\begin{array}{c}\text { Valores organizacionais } \\
\text { percebidos pelos clientes }\end{array}$ & $\begin{array}{c}\text { Valores organizacionais identificados } \\
\text { por Oliveira e Tamayo (2004) }\end{array}$ \\
\hline \multirow{4}{*}{ Respeito aos stakeholders } & Preocupação com a coletividade \\
\cline { 2 - 2 } & Conformidade \\
\cline { 2 - 2 } & Realização \\
\cline { 2 - 2 } & Autonomia \\
\hline Domínio e Poder & Domínio \\
\hline Bem-estar dos empregados & Bem-estar dos empregados \\
\hline \multirow{2}{*}{ Tradição e Prestígio } & Tradição \\
\cline { 2 - 2 } & Prestígio \\
\hline Aversão a mudanças & Tradição \\
\hline
\end{tabular}

Fonte: elaborado pelos autores

\subsection{Análise fatorial das práticas organizacionais percebidas}

As práticas organizacionais percebidas pelos clientes resultaram em quatro fatores. A medida de adequação da amostra (KMO) resultou em 0,980 e a variância explicada pelos fatores correspondeu a $64,3 \%$. Os resultados fatoriais são apresentados na Tabela 2.

0 fator 1, ao qual se denominou Práticas de interação positiva, é composto por itens que expressam a atuação competente dos funcionários, demonstrando conhecimento a respeito do trabalho que fazem; e também por comportamento amistoso e informal, caracterizado por boa vontade, respeito e paciência ao atenderem os clientes, procurando identificar suas necessidades, ouvindo sugestões e estando disponíveis para resolver problemas. Também fazem parte desse fator os itens que expressam a consideração dos funcionários pelos interesses dos clientes e a demonstração de interesse na manutenção do relacionamento. 0 fator 1 também é composto por itens relativos ao comportamento dos funcionários entre si, mostrando que têm senso de equipe e seguem os mesmos critérios de decisão.

0 fator 2, que recebeu o nome Práticas relativas à comunidade, envolve as atuações dos funcionários no sentido de beneficiar a comunidade, contemplando-se aqui os itens que se referem à proteção ao meio ambiente e às campanhas sociais.

0 fator 3, designado como Práticas relativas à concorrência, contempla atuações dos funcionários quanto a oferecer serviços novos ou copiar serviços lançados pelos concorrentes.

Por último, o fator 4, denominado Práticas de interação negativa, envolve as formas de atuação dos funcionários contrárias às expressas no fator 1 , referindo-se à falta de atenção junto aos clientes, à demonstração de negligência e de incompetência para as tarefas a serem realizadas, bem como a falta de procedimentos estabelecidos para a prestação dos serviços. Cabe salientar que os itens que formam o fator 4 apresentaram cargas fatoriais negativas no fator 1 , mostrando-se então como opostos às práticas de interação positiva.

Tabela 2. Resultados fatoriais de práticas organizacionais percebidas.

\begin{tabular}{cccc}
\hline Fator & Autovalor & $\begin{array}{c}\text { \% variância } \\
\text { explicada }\end{array}$ & $\begin{array}{c}\text { Alfa de } \\
\text { Cronbach }\end{array}$ \\
\hline 1 & 21,481 & 45,3 & 0,978 \\
2 & 2,276 & 6,9 & 0,647 \\
3 & 1,457 & 6,1 & 0,708 \\
4 & 1,131 & 6,0 & 0,857 \\
\hline
\end{tabular}

Fonte: Elaborada pelos autores. 


\subsection{Análise fatorial da confiança}

A análise fatorial da confiança resultou em quatro fatores. A medida de adequação da amostra (KMO) foi de 0,937 e a variância explicada pelos fatores correspondeu a 78,1\%. Na Tabela 3 são apresentados os resultados.

0 fator 1 é caracterizado pela Confiança atribuída às organizações, sendo composto por itens relacionados à confiança baseada em conhecimento (fruto do relacionamento e das experiências anteriores junto às empresas), à confiança baseada em identificação (originada da percepção de similaridades e de valores comuns, que leva à estima e ao afeto entre as partes) e à confiança baseada em características (fruto da percepção de características que tornam a outra parte confiável). Esse fator é composto por itens que se referem a experiências anteriores durante a utilização dos serviços, aos sentimentos de estima e afeto para com as organizações e a características que as tornam confiáveis, como infraestrutura adequada, segurança, preocupação com os interesses dos clientes, cumprimento de promessas e competência nas tarefas que realizam.

0 fator 2 recebeu a denominação de Confiança calculativa por ser composto por itens que dizem respeito às vantagens obtidas junto às organizações, envolvendo percepções de que os preços cobrados são inferiores aos da concorrência e de que as condições comerciais são mais vantajosas em relação às oferecidas pelas organizações concorrentes.

0 fator 3 corresponde à Confiança disposicional, que resulta da disposição do indivíduo em confiar, baseada em suas experiências junto a outros indivíduos e situações de um modo geral. Agrega itens que dizem respeito às percepções dos clientes de que as pessoas se preocupam com o bem-estar das outras, costumam cumprir o que prometem e são competentes nas tarefas que realizam.

Finalizando, o fator 4 refere-se à Confiança institucional, a qual diz respeito à crença de que as instituições sociais possam proteger os indivíduos contra riscos, envolvendo as percepções dos clientes de que os órgãos de defesa do consumidor e as leis possam thes amparar no caso das organizações não cumprirem com suas obrigações.

Tabela 3. Resultados fatoriais da confiança.

\begin{tabular}{cccc}
\hline Fator & Autovalor & $\begin{array}{c}\text { \% variância } \\
\text { explicada }\end{array}$ & $\begin{array}{c}\text { Alfa de } \\
\text { Cronbach }\end{array}$ \\
\hline 1 & 10,307 & 44,5 & 0,975 \\
2 & 3,000 & 11,3 & 0,856 \\
3 & 1,700 & 11,2 & 0,823 \\
4 & 1,396 & 11,1 & 0,829 \\
\hline
\end{tabular}

Fonte: Elaborada pelos autores.

\subsection{Modelo da relação entre valores, práticas e confiança dos clientes}

Com o objetivo de testar relações entre os valores organizacionais percebidos, as práticas organizacionais percebidas e a confiança dos clientes, assim como identificar a forma e intensidade como ocorre tal relação, foi utilizada a técnica de modelagem de equações estruturais. Para tanto, os escores fatoriais foram utilizados como indicadores dessas três variáveis latentes (constructos).

0 processamento do modelo contemplando a totalidade dos fatores apresentou resultados pouco acima do desejável para os critérios RMSEA e GFI. A análise dos coeficientes dos indicadores com seus respectivos constructos levou à decisão de eliminar aqueles com baixos coeficientes (betas), como valores organizacionais de domínio e poder $(0,19)$ e de aversão a mudanças $(0,02)$; e confiança calculativa $(0,17)$ e institucional $(0,15)$. Da mesma forma procedeu-se para com as práticas relativas à comunidade e práticas de interação negativa, cujos efeitos estavam sendo captados pelo fator de práticas de interação positiva. Após essa depuração, o modelo final ficou constituído conforme a Figura 1.

Desse modo, o modelo identificado envolveu, no constructo denominado valores organizacionais percebidos pelos clientes, os valores de respeito aos stakeholders, de bem-estar dos empregados e de tradição e prestígio; no constructo conceituado de práticas organizacionais percebidas pelos clientes, as práticas de interação positiva e as práticas relativas à concorrência; e no constructo denominado confiança dos clientes, a confiança atribuída (formada pela confiança baseada em características, em conhecimento e em identificação) e a confiança disposicional.

As medidas de ajuste do modelo identificado, apresentado na Figura 1, são significativas: Chi-square $=53,99 ; \mathrm{df}=11 ; \mathrm{P}$-value $=0,0000$; RMSEA $=0,081 ; \mathrm{GFl}=0,97 ; \mathrm{NNFl}=0,98 ; \mathrm{NFl}=0,98$; $\mathrm{RFI}=0,97 ; \mathrm{IFl}=0,95 ; \mathrm{CFl}=0,99 ; \mathrm{AGFl}=0,92$.

Analisando-se o modelo, é possível observar que os valores organizacionais percebidos pelos clientes, compostos por valores de respeito aos stakeholders, bem-estar dos empregados e tradição e prestígio, possuem elevada correlação $(0,98)$ com as práticas organizacionais percebidas, incluindo-se aqui as práticas de interação positiva e as relativas à concorrência, e que ambos apresentam elevadas correlações com a confiança dos clientes (formada pela confiança atribuída às organizações e a confiança disposicional) correspondendo a $0,92 \mathrm{e}$ 0,95 , respectivamente. Os constructos do modelo apresentaram confiabilidade composta superior ou próxima a 0,7 e variância média explicada superior a $50,0 \%$. 


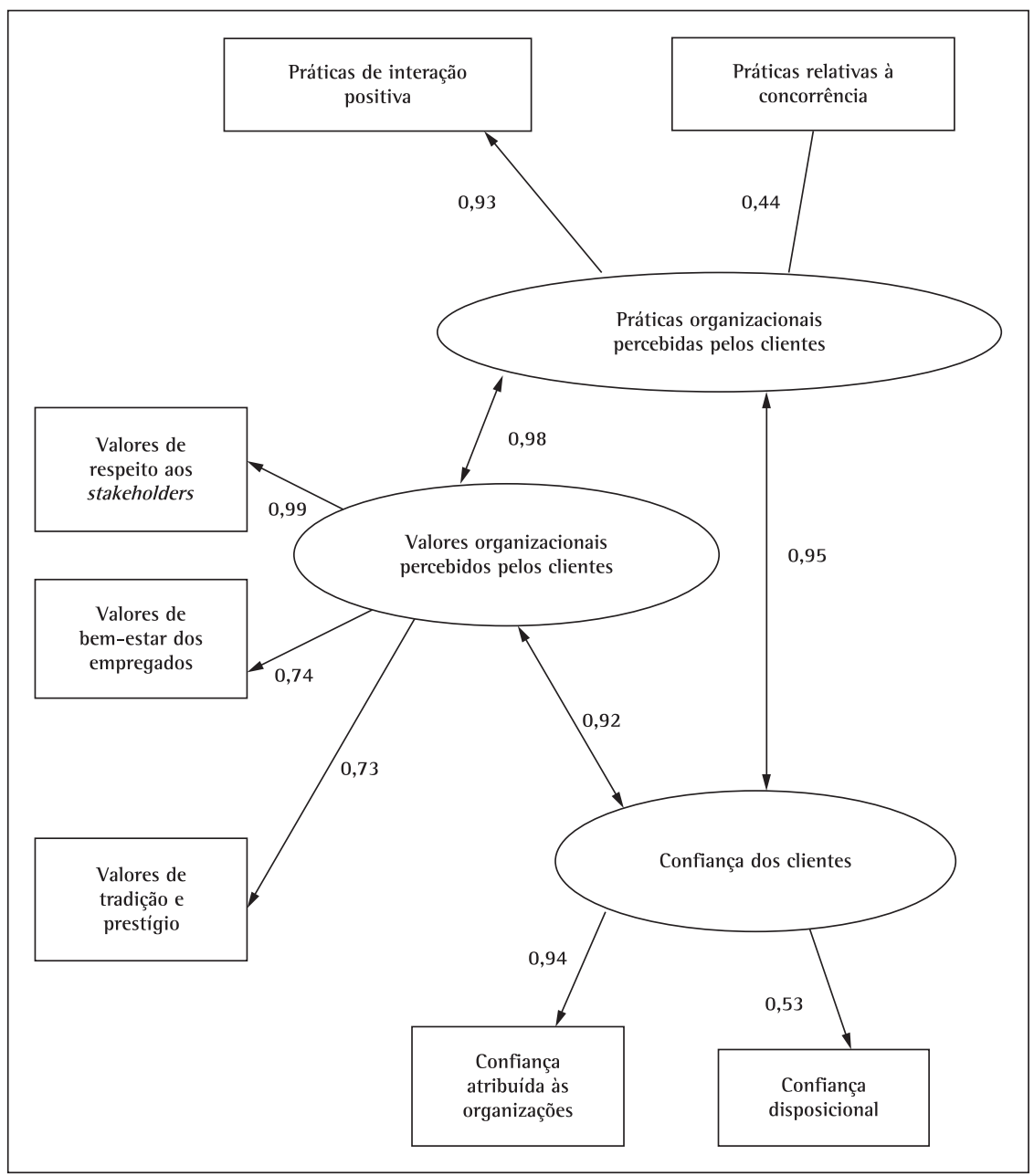

Figura 1. Modelo da relação entre valores e práticas percebidos e a confiança. Fonte: elaborada pelos autores.

Os valores organizacionais percebidos, relacionados com a confiança dos clientes, envolvem os valores de respeito aos stakeholders $(0,99)$, preocupação com o bem-estar dos empregados $(0,74)$ e tradição e prestígio (0,73). A confiabilidade composta desse fator corresponde a 0,739 e sua variância média explicada é de $68,7 \%$. As práticas organizacionais percebidas, relacionadas com a confiança dos clientes, dizem respeito às práticas de interação positiva $(0,93)$ e às práticas relativas à concorrência $(0,44)$. 0 respectivo fator apresenta confiabilidade composta de 0,689 e variância média explicada de 52,9\%. A confiança dos clientes é formada pela confiança atribuída às organizações $(0,94)$, que corresponde à confiança baseada em conhecimento, em características e em identificação; e a confiança disposicional $(0,53)$. Esse fator apresentou confiabilidade composta de 0,697 e variância média explicada de 58,2\%.
Ao se analisar a validade discriminante do modelo, fixando-se em 1,0 a correlação entre os três constructos de forma alternada, identificou-se que o valor de chi-square, originalmente de 53,99 no modelo identificado, aumentou para 69,50 quando se estipulou correlação fixa entre os valores organizacionais percebidos e a confiança dos clientes; e passou a assumir o valor de 60,85 quando se fixou a correlação entre os valores organizacionais e as práticas percebidas. No entanto, ao se fixar a correlação entre as práticas organizacionais percebidas e a confiança dos clientes, o chi-square elevou-se em menos de 3,84, assumindo um valor de 57,34. Sendo assim, identifica-se que não ocorre validade discriminante entre ambos. Porém, apesar de haver validade discriminante nos outros dois casos, é necessário observar o alto valor das correlações, estabelecidas em 0,98 e 0,92, respectivamente. Segundo Kline (2005), a falta de validade discriminante, do ponto de vista estatístico, sugere que os indicadores 
(parcelas) medem apenas um constructo (ou há uma sobreposição de domínios de suas definições). Entretanto, neste estudo, cada dimensão do modelo tem origens, conteúdos e definições distintas, que foram descritas no referencial teórico e na seção dedicada aos procedimentos metodológicos. A seguir, esse resultado é comentado à luz do objetivo da pesquisa e do referencial teórico.

\section{Conclusões}

Identificou-se, sob a perspectiva de clientes de organizações do setor de serviços, relação significativa entre os valores organizacionais percebidos, as práticas organizacionais percebidas e a confiança. Os valores organizacionais percebidos de respeito aos stakeholders; de bem-estar dos empregados e de tradição e prestígio correlacionam-se positivamente com práticas organizacionais de interação positiva e relativas à concorrência. Os valores e práticas correlacionam-se positivamente com a confiança dos clientes, formada pela confiança atribuída (baseada em conhecimento, em características e em identificação) e disposicional.

Os valores organizacionais percebidos que se correlacionam positivamente com a confiança dos clientes envolvem a identificação de princípios que norteiam o comportamento da organização relacionado ao respeito aos stakeholders, caracterizado pela percepção dos clientes de que nessas organizações há preocupação em seguir princípios éticos e morais, em agir conforme as regras, em demonstrar competência para as tarefas desempenhadas e em estimular a inovação e a criatividade. Também envolvem valores percebidos de preocupação quanto ao bem-estar dos empregados bem como o objetivo em ter prestígio junto à sociedade e tradição no mercado. As práticas organizacionais percebidas que se correlacionam positivamente com a confiança dos clientes referem-se basicamente às práticas de interação positiva, caracterizadas por comportamentos que demonstram atenção, paciência e auxílio aos clientes, bem como às práticas relativas à concorrência, as quais se referem a ações no sentido de se manter à frente da concorrência.

A confiança dos clientes é fruto, em parte, de suas tendências pessoais em confiar e, principalmente, do relacionamento que têm com as organizações, em função das experiências anteriores nos momentos de prestação dos serviços, das características que percebem e da identificação que sentem para com as organizações.

Os resultados corroboram a observação expressa por Hofstede et al. (1990), de que os valores não podem ser observados diretamente, mas manifestam-se em alternativas de comportamento. As elevadas correlações entre os valores e as práticas corroboram as colocações de Tamayo e Gondim (1996) de que os valores organizacionais têm implicações nos comportamentos dos membros de uma organização, e que, como comentam Tamayo, Mendes e Paz (2000), funcionam como guias para a ação e para o próprio funcionamento da organização e sua relação com o ambiente. A elevada correlação positiva entre os valores percebidos de respeito aos stakeholders e as práticas percebidas de interação positiva indicam a confirmação do que sugerem Hofstede et al. (1990) e Verbeke (2000), de que as práticas organizacionais estão ligadas aos valores predominantes em cada organização, uma vez que expressam tais valores e que, como salienta Verbeke (2000), refletem características da organização no que tange à sua interação com os diferentes públicos. Assim sendo, os resultados são condizentes com a afirmação de Calori e Sarnin (1991), de que as práticas organizacionais funcionam como manifestações dos valores organizacionais.

A confiança dos clientes envolveu a confiança atribuída às organizações, composta por duas dimensões da confiança abordadas por Hernandez e Mazzon (2005) - confiança baseada em conhecimento e a baseada em características - e pela dimensão abordada complementarmente por Hernandez e Santos (2007), a confiança baseada em identificação. Também envolveu a confiança disposicional, referente à disposição do indivíduo em confiar, baseando-se em suas experiências anteriormente vivenciadas em variadas situações.

Por outro lado, tanto a confiança calculativa, relativa aos riscos assumidos ao confiar, como a institucional, caracterizada pela crença nas instituições sociais, mostraram-se pouco representativas na confiança dos clientes. Destaca-se que a confiança calculativa e a institucional apresentaram correlação significativa apenas junto a valores de domínio e poder, mostrando que, possivelmente, indivíduos que sejam clientes de empresas nas quais identificam valores de domínio e poder, justifiquem o relacionamento pelas vantagens que obtêm e pela crença de que estejam amparados pela lei, mesmo que não percebam valores e práticas que tornem a empresa confiável. Esse aspecto reforça as observações de Hernandez e Mazzon (2005) de que a confiança calculativa está associada a relacionamentos menos estáveis e que, quanto mais longo e satisfatório é o relacionamento dos clientes com uma organização, menos relevantes tornam-se a confiança calculativa e a institucional.

Os resultados obtidos neste estudo mostram que os clientes de organizações de serviços percebem, a partir das interações com os funcionários, valores e práticas organizacionais, o que impacta na confiança que atribuem a essas organizações. Cabe destacar que os dados foram tratados para o setor de serviços 
como um todo, sem diferenciação das correlações e análise fatorial por tipos de serviços. Sugere-se que novas pesquisas sejam realizadas para identificar a estabilidade da estrutura dimensional dos constructos para os diversos estratos do setor, uma vez que diferentes tipos de serviços podem implicar em diferentes percepções por parte dos clientes.

A confiança é um elemento fundamental notadamente em relacionamentos de longo prazo que as empresas desejam conquistar, visando elevar ou diversificar o nível de consumo de seus produtos e serviços e obter recomendação junto a potenciais compradores, dentre outros benefícios. Outros construtos antecedentes à formação da confiança podem ser trabalhados de forma simultânea, sendo esta uma recomendação para estudos subsequentes.

Os resultados abrem, ainda, uma nova possibilidade de estudos em valores organizacionais, apontando para que os mesmos sejam estudados não apenas sob o ponto de vista dos empregados, mas de outros stakeholders, em particular sob a perspectiva dos clientes. Além disso, o estudo limitou-se a consumidores residentes na região metropolitana de São Paulo, sendo desejável que o mesmo seja realizado em outras regiões com características distintas. Dado o caráter não probabilístico da amostra, os resultados obtidos não possibilitam a sua generalização, sendo assim desejável, em termos de direcionamentos futuros, a realização de pesquisas com amostras probabilísticas. Outra sugestão refere-se à identificação de clusters de clientes, avaliando-se o modelo estrutural proposto para cada cluster.

\section{Referências}

AAKER, D. A.; KUMAR, V.; DAY, G. S. Pesquisa de Marketing. São Paulo: Atlas, 2001.

ADAMSON, 1.; CHAN, K. M.; HANDFORD, D. Relationship marketing: customer commitment and trust as a strategy for the smaller Hong Kong corporate banking sector. The International Journal of Bank Marketing, v. 21, n. 6-7, p. 347-358, 2003. http://dx.doi. org/10.1108/02652320310498492

BALL,D.; COELHO,P.S.; MACHÁS, A. The role of communication and trust in explaining customer loyalty. European Journal of Marketing, v. 38, n. 9-10, p. 1272-1293, 2004. http:// dx.doi.org/10.1108/03090560410548979

BARDIN, L. Análise de Conteúdo. Lisboa: Edições 70, 2004.

BRYMAN, A. Social research methods. Oxford: University Press, 2004.

CALORI, R.; SARNIN, P. Corporate culture and economic performance: a french study. Organization Studies, v. 12, n. 1, p. 49-74, 1991. http://dx.doi. org/10.1177/017084069101200104

FERREIRA, M. C. et al. Desenvolvimento de um instrumento brasileiro para avaliação da cultura organizacional. Estudos de Psicologia, v. 7, n. 2, p. 271-280, 2002.
GARBARINO, E.; JOHNSON, M. S. The different roles of satisfaction, trust and commitment in customer relationships. Journal of Marketing, v. 63, n. 2, p. 70-87, 1999. http://dx.doi.org/10.2307/1251946

GOEL, S.; BELL, G. G.; PIERCE, J. L. The perils of Pollyanna: development of the over-trust construct. Journal of Business Ethics, v. 58, n. 1, p. 203-218, 2005. http:// dx.doi.org/10.1007/s 10551-005-1415-6

GRÖNROOS, C. Marketing: gerenciamento e serviços. Rio de Janeiro: Elsevier, 2003.

HAIR JUNIOR, J. F. et al. Análise multivariada de dados. Porto Alegre: Bookman, 2005.

HARISALO, R.; HUTTUNEN, H.; McINERNEY, J. Trust-creating practices for marketing managers. Journal of Change Management, v. 5, n. 4, p. 463-484, 2005. http://dx.doi. org/10.1080/14697010500359280

HERNANDEZ, J. M.; MAZZON, J. A. Trust development in e-commerce and store choice: model and intial test. In: ENCONTRO DA ANPAD, 29., 2005, Brasília. Anais... Rio de Janeiro: ANPAD, 2005.

HERNANDEZ, J. M.; SANTOS, C. C. Proposta para um modelo de mensuração de confiança entre canais de marketing. In: ENCONTRO DA ANPAD, 31., 2007, Rio de Janeiro. Anais... Rio de Janeiro: ANPAD, 2007.

HOFFMAN, K. D.; BATESON, J. E. G. Principios de marketing de serviços: conceitos, estratégias e casos. São Paulo: Pioneira Thomson Learning, 2003.

HOFSTEDE, G. et al. Measuring organizational cultures: a qualitative and quantitative study across twenty cases. Administrative Science Quarterly, v. 35, n. 2, p. 286-316, 1990. http://dx.doi.org/10.2307/2393392

JÖRESKOG, K. G.; SÖRBOM, D. LISREL 8: structural equation modeling with the SIMPLIS command language. Lincolnwood: Scientific Software International, Inc., 1993.

KLINE, R. B. Principles and practice of structural equation modeling. New York: The Guilford Press, 2005.

KLUCKHOHN, C. K. M. Values and value orientation in the theory of action. In: PARSONS, T.; SHILDS, E. (Orgs.). Toward a general theory of action. Cambridge: Harvard University Press, 1951. p. 436-483.

KRAMER, R. M. Trust and distrust in organizations: emerging perspectives, enduring questions. Annual Review of Psicology, v. 50, p. 569-598, 1999. http://dx.doi. org/10.1146/annurev.psych.50.1.569

LEVIN, 1. M. Five windows into orgnization culture: an assessment framework and approach. Organization Development Journal, v. 18, n. 1, p. 83-94, 2000.

LITTLE, T. D. et al. To parcel or not to parcel: exploring the question, weighing the merits. Structural Equation Modeling, v. 9, n. 2, p. 151-173, 2002. http:// dx.doi.org/10.1207/S15328007SEM0902_1

LOVELOCK, C.; WRIGHT, L. Serviços: marketing e gestão. São Paulo: Saraiva, 2001.

MAYER, R.C.; DAVIS, J. H.; SCHOORMAN, D. F. An integrative model of organizational trust. Academy of Management Review, v. 20, n. 3, p. 709-734, 1995.

MEGLINO, B. M.; RAVLIN, E. C. Individual values in organizations: concepts, controversies and research. Journal of Management, v. 24, n. 3, p. 351-389, 1998. 
MORGAN, R. M.; HUNT, S. D. The commitment-trust theory of relationship marketing. Journal of Marketing, v. 58, n. 3, p. 20-38, 1994. http://dx.doi.org/10.2307/1252308

OLIVEIRA, A. F.; TAMAYO, A. Inventário de perfis de valores organizacionais. Revista de Administração, v. 39, n. 2, p. 129-140, 2004.

RANAWEERA, C.; PRABHU, J. The influence of satisfaction, trust and switching barriers on costumer retention in a continuous purchasing setting. International Journal of ServiceIndustryManagement,v. 14, n. 3,p. 374-394, 2003. http://dx.doi.org/10.1108/09564230310489231

ROHAN, M. J. A rose by any name? The values construct. Personality and Social Psychology Review, v. 4, n. 3, p. 255-277, 2000. http://dx.doi.org/10.1207/ S15327957PSPR0403_4

ROKEACH, M. The nature of human values. Nova York: Free Press, 1973.

ROUSSEAU, D. M. et al. Not so different after all: a cross discipline view of trust. Academy of Management Review, v. 23, n. 3, p. 393- 404, 1998. http://dx.doi.org/10.5465/ AMR.1998.926617

SCHWARTZ, S. H. Universals in the content and structure of values: theory and empirical tests in 20 countries. In: ZANNA, M. (Org.). Advances in experimental social psychology. New York: Academic Press, 1992. p. 1-65.

SCHWARTZ, S. H. Are there universal aspects in the structure and contents of human values? Journal of Social Issues, v. 50, n. 1, p 19-45, 1994. http://dx.doi. $\operatorname{org} / 10.1111 /$ j.1540-4560.1994.tb01196.x
SCHWARTZ, S. A theory of cultural values and some implications for work. Applied Psychology, v. 48, n. 1, p. 23-47, 1999. http://dx.doi.org/10.1111/j.1464-0597.1999.tb00047.x

SIRDESHMUKH, D.; SINGH, J.; SABOL, B. Consumer trust, value, and loyalty in relational exchanges. Journal of Marketing, v. 66, n. 1, p. 15-37, 2002. http://dx.doi. org/10.1509/jmkg.66.1.15.18449

TABACHNICK, B. G.; FIDELL, L. S. Using Multivariate Statistic. Boston: Allyn and Bacon, 2001.

TAMAYO, A.; GONDIM, M. G. C. Escala de valores organizacionais. Revista de Administração, v. 31, n. 2, p. 62-72, 1996.

TAMAYO, A.; MENDES, A. M.; PAZ, M. G. T. Inventário de valores organizacionais. Estudos de Psicologia, v. 5, n. 2, p. 289-315, 2000. http://dx.doi.org/10.1590/S1413294X2000000200002

VERBEKE, W. A revision of Hofstede et al.'s (1990) organizational practices scale. Journal of Organizational Behavior, v. 21, n. 5, p. 587-602, 2000. http://dx.doi. org/10.1002/1099-1379(200008)21:5<587::AlDJOB22>3.0.CO;2-5

WALTER, A.; RITTER, T. The influence of adaptations, trust, and commitment on value-creating functions of customer relationships. Journal of Business Industrial Marketing, v. 18, n. 4, 2003. http://dx.doi.org/10.1108/08858620310480250

ZEITHAML, V. A.; BERRY, L. L.; PARASURAMAN, A. The behavioral consequences of service quality. Journal of Marketing, v. 60, n. 2, p. 31-46, 1996. http://dx.doi. org/10.2307/1251929

\title{
The relationship between values, organizational practices and customers trust in the services sector
}

\begin{abstract}
Personal values influence individual behavior and organizational values influence the organizational practices development. However, there is no study linking these constructs with client's trust. This study analyzed, according to the perspective of customers, the relationship between perceived organizational values, perceived practices, and trust in organizations. After a qualitative research, an organizational practices scale was elaborated. An organizational values scale and a trust scale were adapted. The model test of the relationship between the constructs was based on a survey using a costumer's sample. The data were processed by software LISREL 8.7. The results showed that the organizational values perceived are positively correlated with the practices and both constructs are significant and positively correlated with costumers' trust.
\end{abstract}

Keywords

Organizational values. Practices. Trust. Services. 